\title{
System Reliability of Bridge Structure Subjected to Chloride Ingress
}

\author{
Bernt J. Leira ${ }^{1}$, Sebastian Thöns ${ }^{2}$, Michael H. Faber ${ }^{3}$

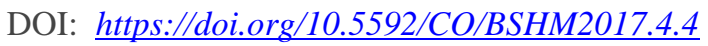 \\ ${ }^{1}$ NTNU, Dept. Marine Technology, Otto Nilsens vei 10, Trondheim, 7491, Norway \\ ${ }^{2}$ DTU, Dept. Structural Eng., Bygning 118, Brovej, Kongens Lyngby, 2800, Denmark \\ ${ }^{3}$ DTU, Dept. Management Eng., Bygning 424, Nils Koppels Alle, Kongens Lyngby, 2800, Denmark \\ E-mails: ${ }^{1}$ Bernt.Leira@ntnu.no; ${ }^{2} S e b t @ b y g . d t u . d k ;{ }^{3} M i h f @ d t u . d k$
}

\begin{abstract}
The parameters relevant for prediction of service lifetime with respect to chloride ingress are associated with large uncertainties. Full-scale measurements are in demand for conditions which are as homogeneous as possible. The present paper first summarizes statistical distributions which are obtained based on measurements from the Gimsøystraumen bridge in Norway. A large number of chloride profiles are available, and for each of these the diffusion coefficient and surface concentration (due to sea-spray) are estimated. Extensive measurements of concrete cover are also performed. These probability distributions are subsequently employed as input to a prediction model for chloride concentration at the steel reinforcement for a single but arbitrary position along the reinforment. Since the input parameters are represented in probabilistic terms, the chloride concentration is also a stochastic quantity. Furthermore, introducing the critical chloride concentration on a similar form, the probability of exceeding the critical threshold is determined as a function of time.
\end{abstract}

In order to address chloride attack on the entire bridge, a system model with 90 components is next introduced. This model is employed in order to perform reliability updating based on observations at a number of sites along the bridge. First-order (FORM) reliability methods typically become inaccurate for large systems of this type. Crude Monte Carlo Simulation (which can be more accurate) will easily demand impractical efforts in terms of CPU-time, and a more efficient Monte Carlo simulation method is accordingly applied. It is shown that this typically reduces computation times by a factor of around 10.

Keywords: System reliability; Enhanced Monte Carlo; Chloride ingress; Bridge test data.

\section{Introduction}

A large number of chloride profiles have been obtained from the Gimsøystraumen bridge which is located in the Northern part of Norway. For the superstructure profiles from 725 locations were collected. For the columns sampling was performed for 168 locations (Skjølsvold, 2001). For each of the profiles, the corresponding diffusion coefficient and the chloride surface concentration were estimated. Extensive measurements of concrete cover were also performed. (Note: The values for statistical values given herein may deviate slightly from those of (Skjølsvold, 2001) due to further refinement of the chloride profile data in that report).

The corresponding probability distributions are subsequently employed as input to a model for prediction of chloride concentration at the steel reinforcement. As the input parameters are represented in probabilistic terms, the chloride concentration accordingly becomes a stochastic quantity. The critical chloride concentration is also introduced on a similar form. As the next step, the resulting probability that the concentration at the reinforcement exceeds the critical threshold is then determined as a function of time, see also (Hynne et. al., 2001). Parameter variations are performed with respect to the input statistical models. In particular, the effect of introducing a diffusion coefficient which varies with time is investigated.

In order to address chloride attack on the entire bridge, a system model with 90 components is next introduced. This model is employed in order to perform reliability updating based on observations at a number of sites along the bridge. The computations are performed by application of the so-called enhanced Monte Carlo simulation method (Næss et. al., 2009 \& 2012). 


\section{Probabilistic modelling based on full-scale measurements}

\subsection{General}

The Gimsøystraumen bridge is located in the Lofoten area in Northern Norway, see Figure 1. This bridge has served as a "test bridge" for many purposes including assessment of different types of repair methods.

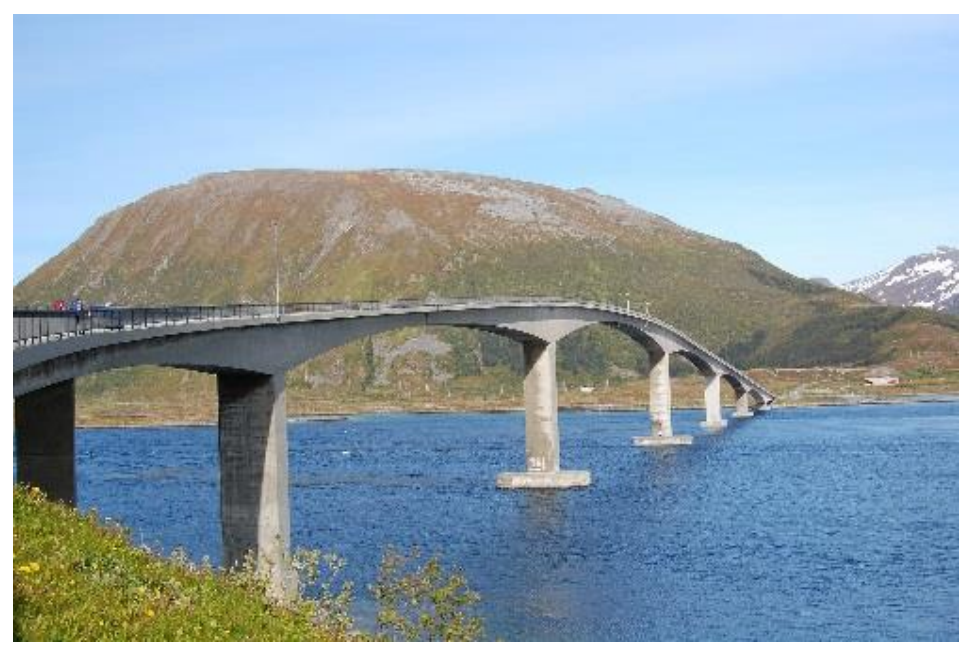

Fig 1. The Gimsøystraumen bridge in Northern Norway (Lofoten area)

The objective of the present study is to assess the merits of relevant probabilistic models based on fullscale data and to show how they can be applied for the purpose of lifetime assessment with respect to chloride ingress.

Furthermore, it is intended to illustrate how information from monitoring and inspection can serve the purpose of reliability updating. In order to achieve a realistic model of the entire bridge structure, a system model is subsequently established. As computation of the corresponding system reliability as a function of time easily becomes quite demanding, it is also demonstrated how so-called enhanced Monte Carlo Techniques can serve to make calculation of the structural reliability more efficient than the crude Monte Carlo techniques (abbreviated simply as MC)

\subsection{Statistical analysis of test data}

For each of the three parameters that were measured or estimated based on the measurements (i.e. diffusion coefficient, surface concentration and concrete cover), the applicability of various analytical probability distributions were tested by plotting in different types of probability paper. A ranking was performed based on the regression coefficients. As an example, a summary of the results are shown in Table 1 for the diffusion coefficients obtained for the east side of the columns.

Table 1. Diffusion coefficient (Multiplication by $10^{-12}$ gives the values in $\mathrm{m}^{2} / \mathrm{s}$ )

\begin{tabular}{|c|c|c|c|c|c|}
\hline Prob. model & Regression line & $\begin{array}{l}\text { Mean } \\
\text { value }\end{array}$ & $\begin{array}{l}\text { Standard } \\
\text { deviation }\end{array}$ & $\begin{array}{l}\text { Sample } \\
\text { variance }\end{array}$ & $\mathbf{R}^{2}$ \\
\hline Normal & $y=1.6051 x-2.0384$ & \multirow{4}{*}{1.27} & \multirow{4}{*}{0.64} & \multirow{4}{*}{0.41} & 0.9815 \\
\hline Gamma & $y=0.7388 x-0.6466$ & & & & 0.7934 \\
\hline Weibull & $y=2.3307 x-0.8316$ & & & & 0.9948 \\
\hline Lognormal & $y=1.9765 x-0.1641$ & & & & 0.9809 \\
\hline
\end{tabular}



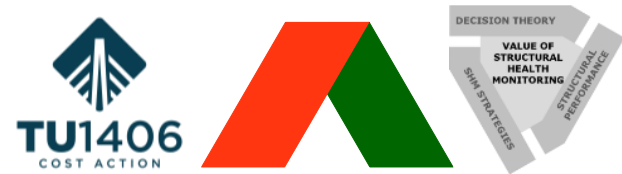

As observed, the Weibull distribution gives the highest regression coefficient, $\mathrm{R}^{2}$. The measured and analytical distribution functions as plotted in Weibull probability paper are compared in Figure 2. However, in general all the different distributions give quite high values for the regression coefficient.

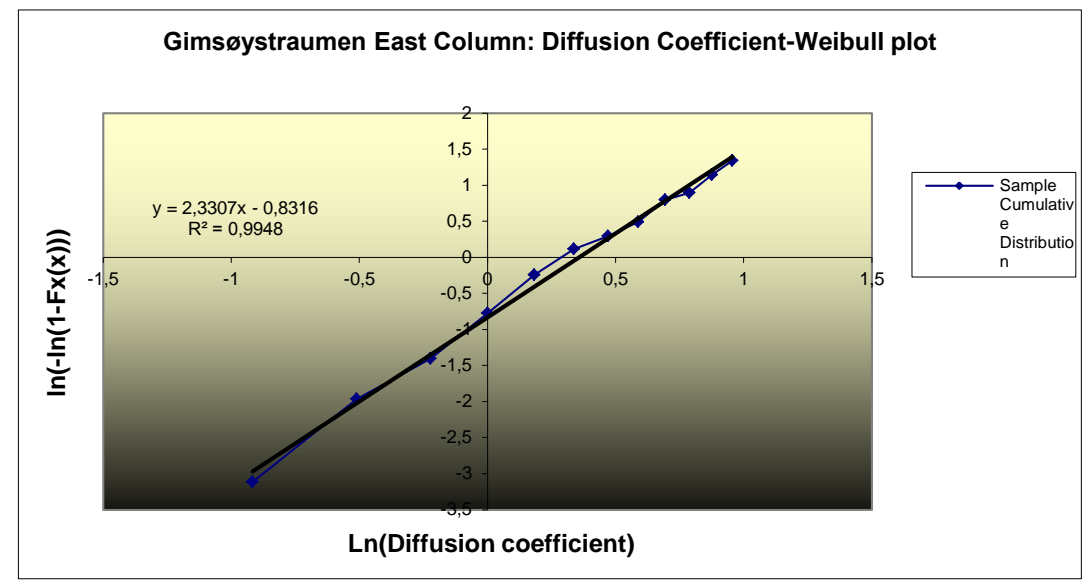

Fig. 2. Comparison between sample distribution function and fitted Weibull distribution for the diffusion coefficient, east side of columns.

A more direct comparison between the analytical model and the observed data is provided by considering the density function, i.e. the expected number versus the observed number of samples within each discretized interval. Such a comparison is provided by Figure 3. The overall comparison is quite good, but with some "oscillations" around the theoretical curve

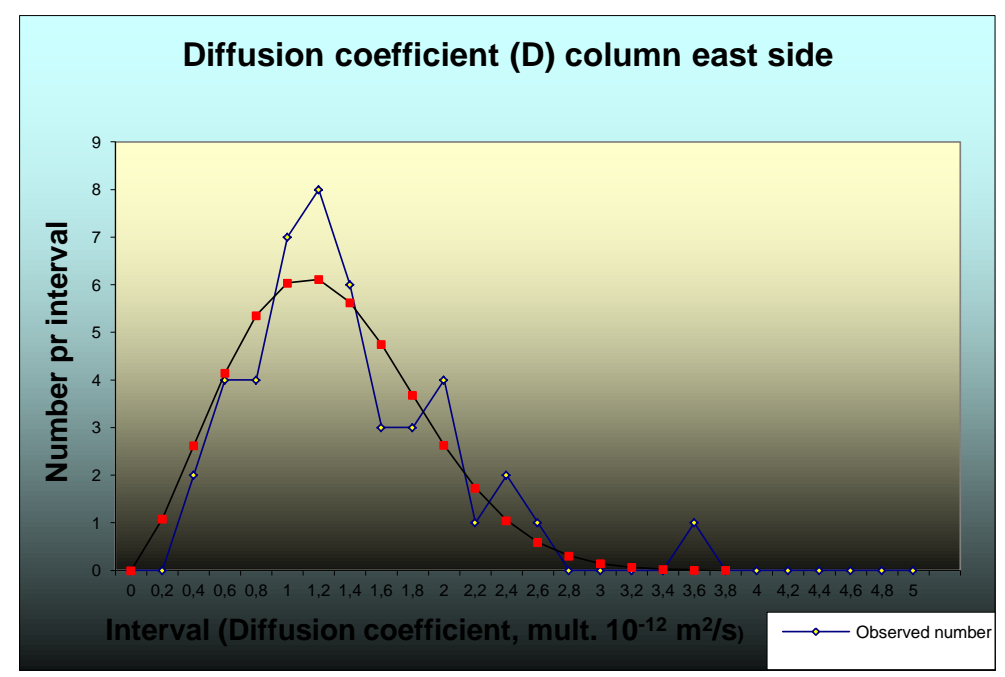

Fig. 3. Observed versus predicted number of samples for the diffusion coefficient within each interval, east side of columns. Theoretical model is based on regression curve in Figure 2.

Although the Weibull model gave the best fit for this specific case, it is found that on the average, the lognormal probability distribution gives the best fitting. Furthermore, there are reasons of convenience for selecting this model when calculating the probabilistic lifetime distributions. Hence, the lognormal distribution is applied for the present calculations of lifetime distributions. 
The regression coefficients obtained from a similar fitting of probability distributions for the chloride surface concentration are shown in Table 2. It is observed that the lognormal distribution gives the highest value for the regression coefficient. However, all the distributions have regression coefficients higher than 0.9 , which in general is quite acceptable.

Table 2. Surface concentration, $\mathrm{C}_{\mathrm{s}}(\%$ of concrete weight $)$

$\begin{array}{llccrr}\text { Probabilistic model } & \text { Regression line } & \begin{array}{l}\text { Mean } \\ \text { value }\end{array} & \begin{array}{c}\text { Standard } \\ \text { deviation }\end{array} & \begin{array}{l}\text { Sample } \\ \text { variance }\end{array} & \mathbf{R}^{\mathbf{2}} \\ \text { Normal } & \mathrm{y}=3.5447 \mathrm{x}-1.5979 & & & & 0.9156 \\ \text { Gamma } & \mathrm{y}=1.4932 \mathrm{x}-0.3422 & & & 0.9352 \\ \text { Gumbel } & \mathrm{y}=4.0841 \mathrm{x}-1.3635 & 0.50 & 0.34 & 0.11 & 0.9716 \\ \text { Weibull } & \mathrm{y}=1.9038 \mathrm{x}+1.2355 & & & 0.9338 \\ \text { Lognormal } & \mathrm{y}=1.4879 \mathrm{x}+1.3571 & & & 0.9826\end{array}$

The corresponding sample distribution function and the fitted lognormal model are shown in Figure 4. It is seen that the upper part of the empirical distribution (which is most relevant for the shortest lifetimes) is also fitted well by this analytical model.

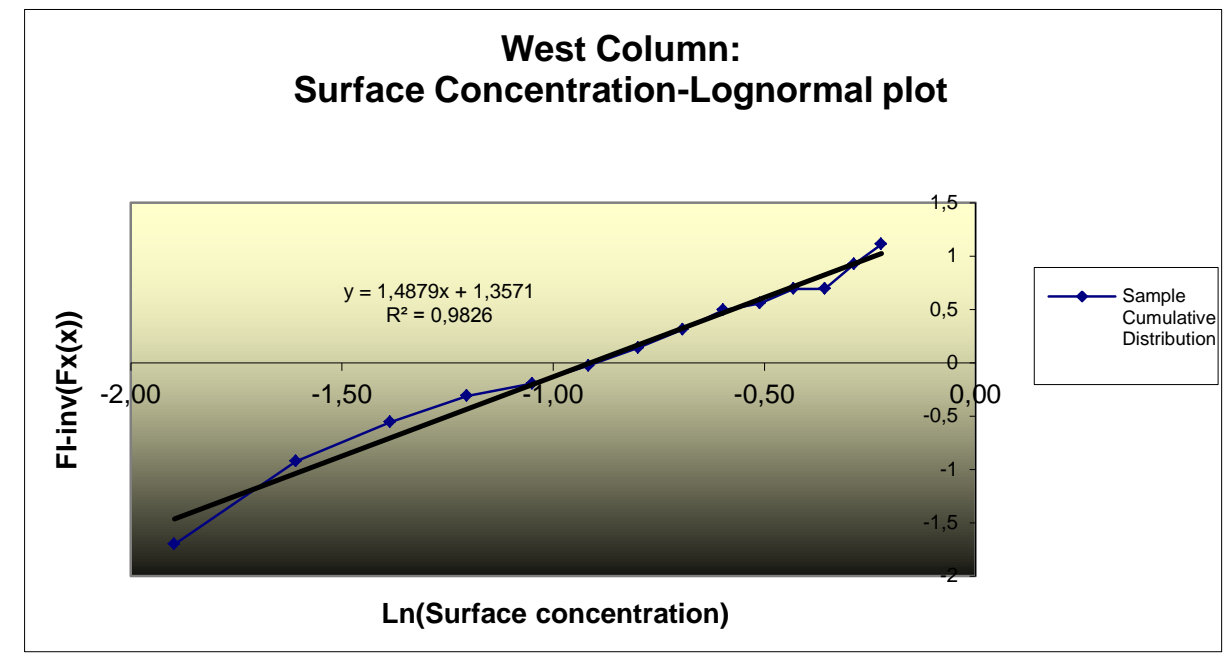

Fig. 4. Cumulative distributions for measured surface concentration plotted in lognormal scale, and resulting fitted lognormal model. West side of columns.

Measurements of concrete cover depth were also performed. A lognormal model was found to give the best fit to the measurements. Based on the full-scale measurements and consideration of the additional parameters entering into the computation of chloride lifetime, corresponding probabilistic models are established. The relevant parameters are defined in relation to the solution of Fick's second law for the chloride concentration $\mathrm{c}(\mathrm{x}, \mathrm{t})$ at position $\mathrm{x}$ and at time $\mathrm{t}$ :

$c(x, t)=c_{i}+\left(c_{\mathrm{s}}-c_{i}\right) \cdot \operatorname{erfc}\left(\frac{x}{2 \sqrt{D \cdot t}}\right)$

where $c_{i}$ is the initial chloride concentration in the concrete, $c_{s}$ is the chloride concentration at the surface, and D is the diffusion coefficient. The concentration at the position of the reinforcement is subsequently compared to the critical chloride concentration for onset of corrosion. The diffusion coefficient may furthermore be time-dependent. The time variation is here expressed by the so-called alfa-factor (Maage et. al., 1994 and Poulsen, 1996). The value of the alfa-factor influences the time variation of the diffusion coefficient through the following expression: (talfa). Accordingly, alfa equal to zero corresponds to a constant diffusion coefficient while alfa $=1$ corresponds to a linear increase with time etc. 

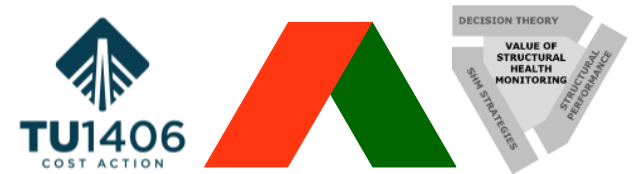

The probabilistic models which applied for the superstructure are summarized in Table 3 . The model uncertainty factor which occurs both in Table 3 and Table 4 is introduced in order to account for deviations between model predictions and observed diffusion rates. The lowest value is taken to represent lifetime calculations performed for the bridge from which the measurement were performed. The highest value could e.g. represent a situation where these particular data were applied for calculations of a "similar" bridge.

Table 3. Statistical distributions for superstructure

$\begin{array}{llll}\text { Statistical variable } & \text { Distribution type } & \text { Mean value } & \text { Standard deviation } \\ \text { Surface concentration } & \text { Lognormal } & 0.25(\% \text { concrete weight }) & 0.18(\% \text { concrete weight }) \\ \text { Diffusion coefficient } & \text { Lognormal } & 0.88\left(\mathrm{~m} 2 / \mathrm{sec}, \text { mult } 10^{-12}\right) & 0.68\left(\mathrm{~m} 2 / \mathrm{sec}, \text { mult } 10^{-12}\right) \\ \alpha \text {-factor (time-var. of diff. coef.) } & \text { Deterministic } & 0.0 & - \\ \text { Initial concentration } & \text { Normal } & 0.015(\% \text { concr. wght. }) & 0.0015(\% \text { concrete weight }) \\ \text { Concrete cover } & \text { Lognormal } & 23 \mathrm{~mm} & 6 \mathrm{~mm} \\ \text { Critical chloride concentration } & \text { Lognormal } & 0.18(\% \text { concr. weight }) & 0.06(\% \text { concrete weight }) \\ \text { Model uncertainty } & \text { Normal } & 1.0 & 0.01 / 0.10\end{array}$

Corresponding models which apply to the columns are given in Table 4. As observed, both the diffusion coefficient and the surface concentration are higher for this case. However, the concrete cover is also considerably thicker than for the superstructure.

Table 4. Statistical distributions for columns

$\begin{array}{llll}\text { Statistical variable } & \text { Distribution type } & \text { Mean value } & \text { Standard deviation } \\ \text { Surface concentration } & \text { Lognormal } & 0.50(\% \text { concrete weight }) & 0.34(\% \text { concrete weight }) \\ \text { Diffusion coefficient } & \text { Lognormal } & 1.27\left(\mathrm{~m} 2 / \mathrm{sec}, \text { mult } 10^{-12}\right) & 0.64\left(\mathrm{~m} 2 / \mathrm{sec}, \text { mult } 10^{-12}\right) \\ \alpha \text {-factor (time variation) } & \text { Deterministic } & 0.0 & - \\ \text { Initial concentration } & \text { Uniform } & 0.015(\% \text { concrete weight }) & 0.0015(\% \text { concrete weight }) \\ \text { Concrete cover } & \text { Lognormal } & 45 \mathrm{~mm} & 6 \mathrm{~mm} \\ \text { Critical chloride concentration } & \text { Lognormal } & 0.18(\% \text { concrete weight }) & 0.06(\% \text { concrete weight }) \\ \text { Model uncertainty } & \text { Normal } & 1.0 & 0.01 / 0.10\end{array}$

\section{Lifetime distributions based on the measured data}

\subsection{Base case analysis}

The cumulative distribution functions for chloride lifetime which are obtained by calculating probabilities of the type: $\mathrm{P}$ (chloride concentration at reinforcement at time $\mathrm{t}<$ critical chloride concentration). These probabilities are computed repeatedly for a number of different values of the time parameter. The calculations are performed by application of so-called First Order Reliability Methods (FORM), see e.g. (Madsen et. al. 1986).

The probability distribution that results from reliability analysis based on the input data given in Table 3 (superstructure), is shown in Figure 5. The corresponding probability density function is obtained by numerical differentiation and is given in Figure 6. As observed, the peak of the latter occurs for a lifetime of 6 years. However, the shape of the upper tail is such that it decays very slowly. This implies a large standard deviation for the lifetime. This is also reflected by the distribution function rising very slowly.

This distribution function obtains a value of 0.4 for a duration of 80 years. This implies that the probability for the lifetime to be smaller than this value is $40 \%$. 


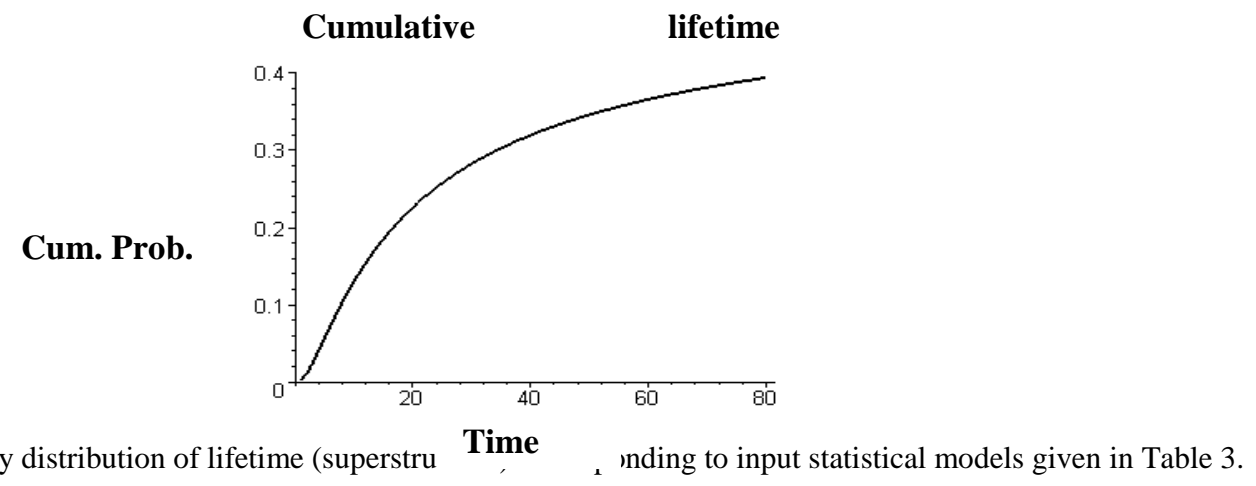

Fig. 5 Probability distribution of lifetime (superstru Time , inding to input statistical models given in Table 3.

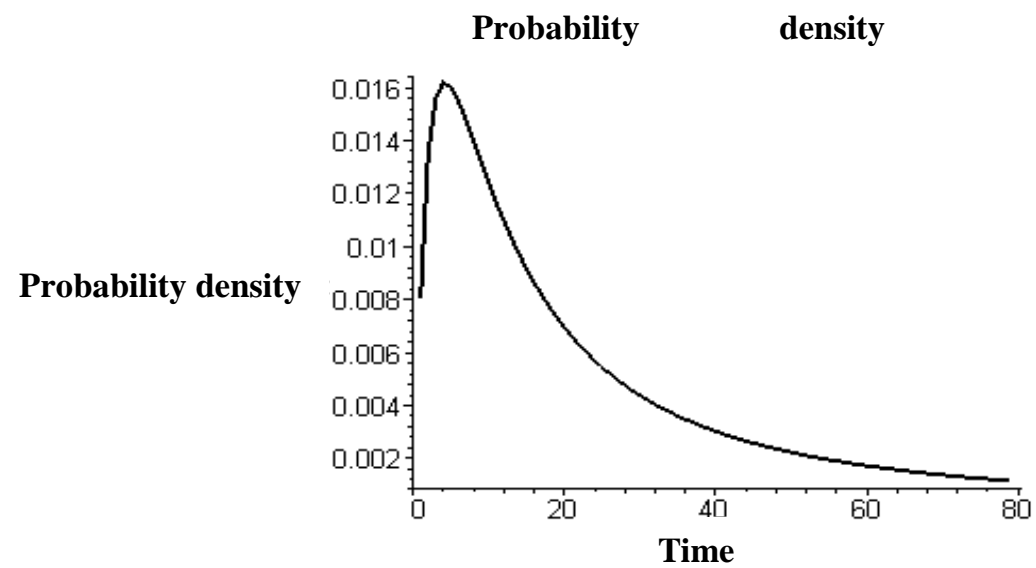

Fig. 6. Probability density function obtained by differentiation of distribution function in Figure 5.

\subsection{Parametric variations}

The effect of varying the statistical parameters of the input models can be readily studied. The effect of including a probabilistic time varying diffusion is accounted for by introducing the alfa-parameter as discussed above. This is presently done by modelling this parameter as a random variable. The mean value is taken to be 0.4 , and the standard deviation is 0.1. A lognormal distribution is assumed to apply. The resulting cumulative distribution of the lifetime and the corresponding density function are shown in Figures 7 and 8. These should be compared to the distribution and density functions presented in Figures 5 and 6.

\section{Cumulative lifetime distribution}

Cum. Prob.

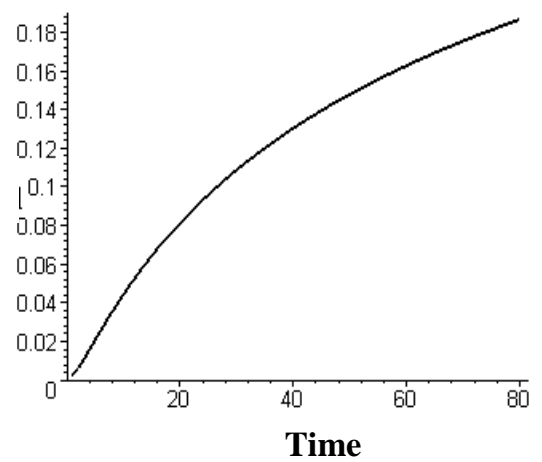

Fig. 7. Cumulative distribution function for chloride lifetime. Alfa-parameter which defines variation of diffusion coefficient with time is represented by a lognormal distribution with mean value 0.4 and a standard deviation of 0.1 

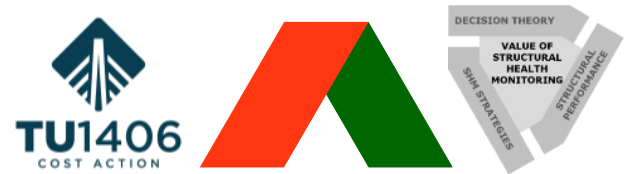

\section{Probability density function}

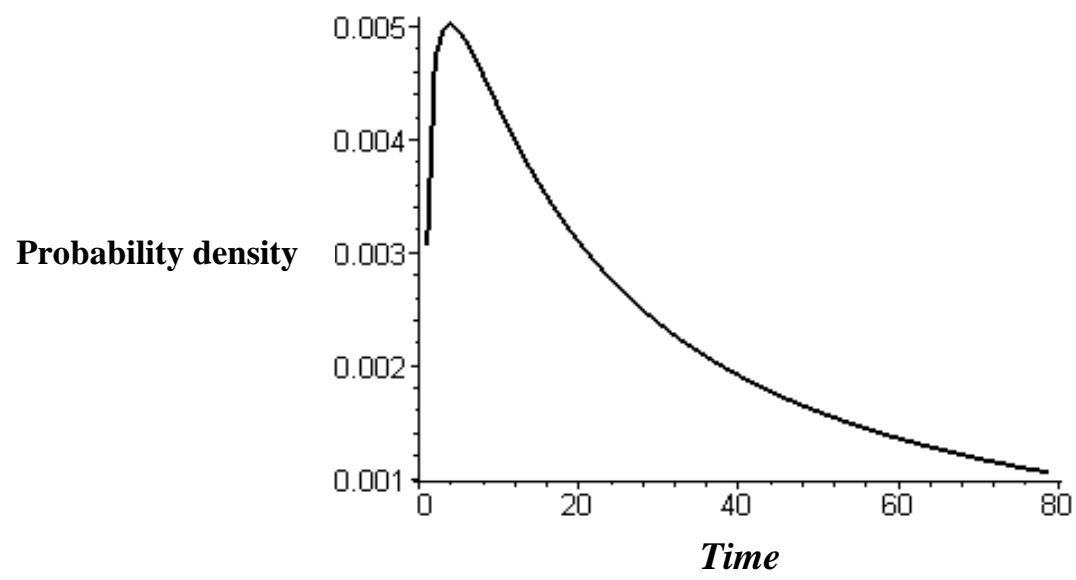

Fig. 8. Probability density function corresponding to the distribution function in Figure 7.

The peak of the density function is still located at 6 years. However, the peak is now much smaller than in Figure 6. The upper tail of the density is also higher, and the corresponding distribution function in Figure 7 is "stretched" towards higher lifetimes as could be anticipated.

\section{Reliability updating for system model of entire bridge structure by enhanced Monte Carlo simulation}

\subsection{General}

The analysis so far has basically been relevant for only a single "spot" or "component". A more realistic model corresponds to analysis of the whole bridge structure, which implies that assessment of the corresponding system reliability needs to be made.

This requires a more complex analysis where FORM/SORM techniques easily become inadequate, or at least inaccurate. Resort must typically be made to Monte Carlo simulation methods which can provide more accurate results, but which at the same time are quite demanding with respect to computation time.

This calls for more efficient simulation methods, and in the present study the enhanced Monte Carlo simulation technique (which was referred to above) is applied. In general, this approach is based on introduction of a scaling parameter $\lambda$ for the limit state function. A scaling factor of 1.0 corresponds to the "true" failure function while a value smaller than one leads to higher failure probabilities (i.e. a less reliable structural system). In the present application, a similar scaling is also introduced for the "observation function" which represents additional information that has become available based on e.g. monitoring or inspection of the structure.

\subsection{Simplified system model of bridge superstructure}

The bridge superstructure is considered to consist of 3 sites (i.e. "components") in the transverse direction and 30 segments in the longitudinal direction, giving at total of $3 \times 30=90$ components. In the transverse direction, each component represents the chloride ingress for one of the "faces" of the box girder, i.e. the windward face, the downward face and the leeward face. The roadway itself is not 
included as the surface chloride concentration is much lower for this part then the others. In the longitudinal direction, each component represents a certain length segment of each of the faces.

A simplified analysis is applied where only the surface concentration is represented as a random variable (while the other random variables are modelled as deterministic quantities equal to the mean values of the corresponding variables in the table above). The initial chloride concentration at the steel armour is set to zero.

For this purpose, the surface chloride concentration is represented by a mean value of $0.14 \%$ and a standard deviation of $0.028 \%$. (Instead of lognormal model, a Gaussian model is applied which is truncated at a value of $0.1 \%$ for the surface concentration). These values correspond to a situation where the failure probability for a single component as well as the entire bridge system is much smaller than for the previous case where models based on full-scale observations for the particular bridge were applied.

Presently, identical values are applied for the surface concentration of all "components" and accordingly the failure functions are the same for all the components. However, the concentrations at different sites are assumed to be completely independent from each other which implies that 90 independent random variables are introduced.

\subsection{Reliability updating based on inspection of surface concentration}

First a system reliability analysis is performed based on the assumptions described above. Furthermore, a system failure probability is evaluated at a time in operation of $t=60$ years. The corresponding failure probability is shown as a function of the scaling parameter in Figure 9 below for the case that no additional information from monitoring or inspection is available. The 95\% confidence band is also shown as represented by the upper and lower curves.

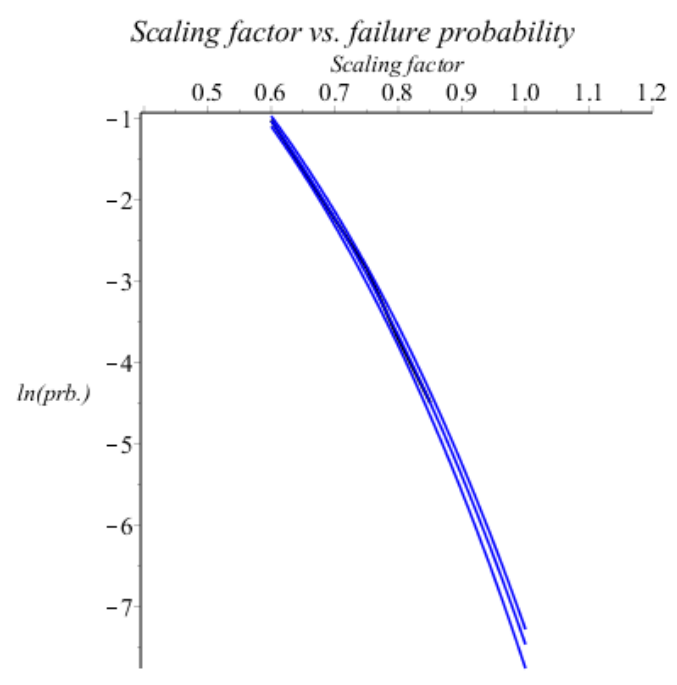

Figure 9. Failure probability as a function of the scaling parameter at a time of $t=60$ years without any additional information (from monitoring or inspection) being available.

The corresponding estimated failure probability for the system with 90 components (i.e. for the scaling parameter $\lambda=1.0)$ is computed as $5.72 \mathrm{e}-4$ with the $95 \%$ confidence interval being $(4.78 \mathrm{e}-4,6.58 \mathrm{e}-4)$. This implies that the coefficient of variation for the estimated failure probability is around $5 \%$. The total number of samples is 32000 , which corresponds to a reduction by a factor of around twenty as compared to what would be required by crude Monte Carlo simulation in order to achieve the same level of accuracy.

It is next assumed that the surface concentrations for half the components are found to be lower than the mean value plus two standard deviations, i.e. $0.196 \%$. The results based on enhanced Monte Carlo 

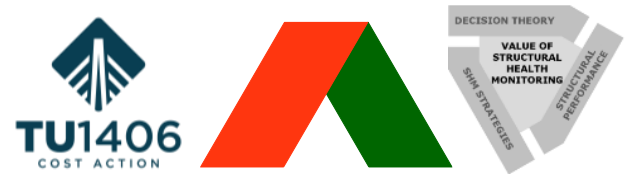

simulation for the new updated failure probability at $\mathrm{t}=60$ years are shown in Figure 10 for increasing values of the scaling parameter(which is applied both for the failure function and for the observation function).

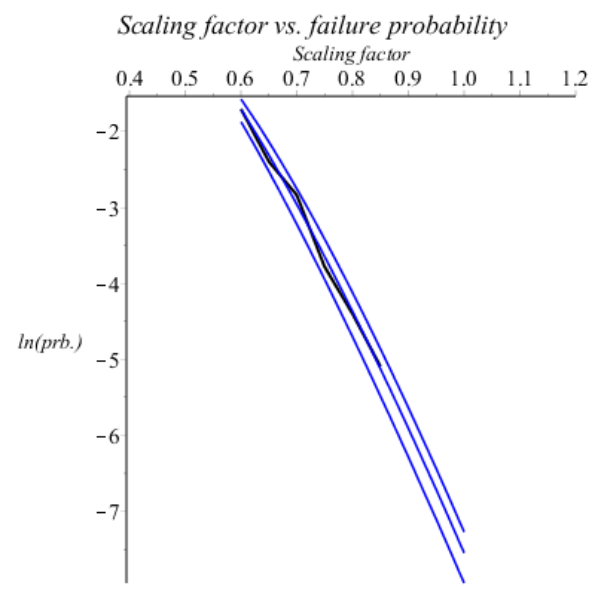

Figure 10. Failure probability as a function of the scaling parameter for system with 90 components subjected to chloride ingress. Failure probability at $\mathrm{t}=60$ years for the case that the surface concentrations for half the components are found to be smaller than $0.196 \%$.

The estimated failure probability for the system with 90 components (i.e. for the scaling parameter $\lambda=$ $1.0)$ is now found to be $5.26 \mathrm{e}-4$ with the $95 \%$ confidence interval being $(3.53 \mathrm{e}-4,6.93 \mathrm{e}-4)$. This implies that the coefficient of variation for the estimated failure probability is around $15 \%$. The total number of samples is 16000 , which also now corresponds to a reduction by a factor of six as compared to what would be required by crude Monte Carlo simulation.

We next assume that the surface chloride concentration is less than the critical value $0.18 \%$ (for half the "sites/components"). The results for this case are shown in Figure 11.

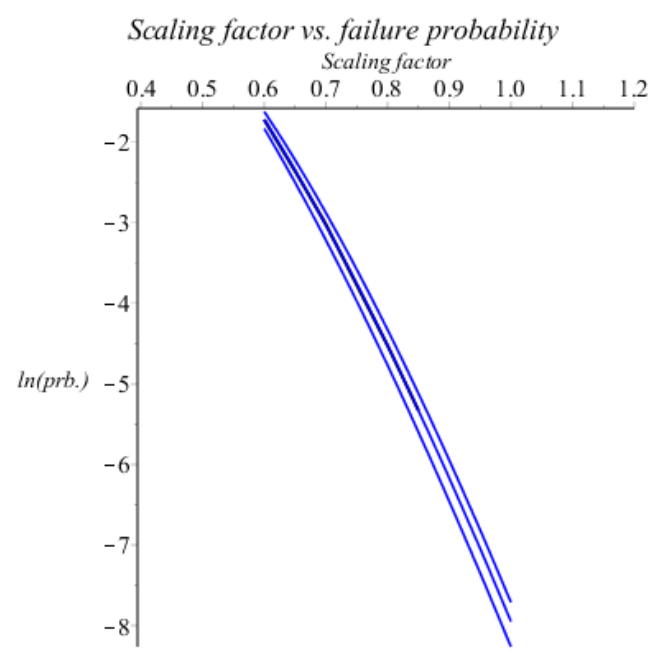

Figure 11. Failure probability as a function of the scaling parameter for system with 90 components subjected to chloride ingress. Failure probability at $\mathrm{t}=60$ years for the case that the surface concentrations for half the components are found to be smaller than $0.18 \%$.

The estimated failure probability for the system with 90 components (i.e. for the scaling parameter $\lambda=$ 1.0 ) is now found to be $3.52 \mathrm{e}-4$ with the $95 \%$ confidence interval being $(2.57 \mathrm{e}-4,4.48 \mathrm{e}-4)$. This implies that the coefficient of variation for the estimated failure probability again is around $15 \%$. The 
total number of samples is 20 000, which still corresponds to a reduction by a factor of six as compared to crude Monte Carlo simulation.

For the present analysis, independence between the "components" was assumed. The corresponding effect of having additional information on the resulting system reliability was a reduction of the failure probability roughly by a factor of three. If correlation between the components was introduced the effect would be much more pronounced. If full correlation would apply, this essentially means that there is only a single component in the system rather than 90 . Accordingly, the failure probability would be reduced by a similar factor even if only a single component was inspected.

\section{Concluding remarks}

In the present paper, probabilistic models based on full-scale measurements from the Gimsøystraumen bridge are addressed. These models apply to the diffusion coefficient, the chloride surface concentration and the concrete cover. Based on these models and supplementary models for other parameters affecting chloride diffusion, probabilistic lifetime calculations are performed.

A system reliability analysis method was introduced and subsequent reliability updating was performed by means of enhanced Monte Carlo simulation. As a general observation, it was found that the computational effort (as measured by CPU-time) was typically reduced by a factor of six.

There are clearly multiple future research topics that should be addressed. Examples are: The effect of correlation between the system components in connection with the updated reliability, the effect of non-identical system components, combination of parallel and series system models of bridge systems and Ultimate Limit State criteria in addition to Serviceability criteria.

\section{Acknowledgements}

The data basis for the present work was established during the project "The lifetime of concrete structures" (Betong-konstruksjoners Livsløp) which was performed by the Norwegian Public Roads Administration. The digital background material for the present paper was provided by a number of persons, in particular Finn Fluge, Ola Skjølsvold, Trine Hynne, and Jan-Erik Carlsen. Their contributions are greatly acknowledged.

\section{References}

Skjølsvold, O.: "Gimsøystraumen Bru. Spesialinspeksjon 1992 - kloridprofiler. Vurdering av kloridbelastning og - diffusjonskoeffisient” (in Norwegian), Internal Report no. 2196, Road Technology Department (NRRL), Norwegian Public Roads Administration, April, 2001.

Hynne, T.; Leira, B.J.; Carlsen, J.E. and Lahus, O.: "Statistiske levetidsberegninger for betongkonstruksjoner utsatt for kloridinntrengning" (in Norwegian), SINTEF Report, STF22 F01613, Project report no DP1 B1, "The lifetime of concete structures",Trondheim, 2001.

Madsen, H.O.; Krenk, S.; Lind, N.C.: "Methods of Structural Safety", Prentice-Hall, Englewood Cliffs, NJ, 1986.

Maage, M; Poulsen,E.; Vennesland,Ø and Carlsen J.E.:’Service Life Model for Concrete Structures exposed to Marine Environment", LIGHTCON report DP 2-7, STF70 94082, SINTEF, Trondheim, Norway, 1994.

Naess, A.; Leira, B.J. \& Batsevych, O. : System reliability analysis by enhanced Monte Carlo simulation. Structural Safety 31: 349-355, 2009.

Naess, A.; Leira, B.J. \& Batsevych, O. : Reliability analysis of large structural systems. Probabilistic Engineering

Mechanics, 28: 164-168, 2012. 
Poulsen, E.:'Estimation of Chloride Ingress into Concrete and Prediction of Service Lifetime with reference to Marine RC Structures", Proceedings of CEMENTA's Workshop on "Durability of Concrete in Saline Environment", Danderyd, Sweden, 1996.

Thoft-Christensen, P. and Baker, M.:’Structural Reliability Theory and Its Applications”, Springer, 1982. 